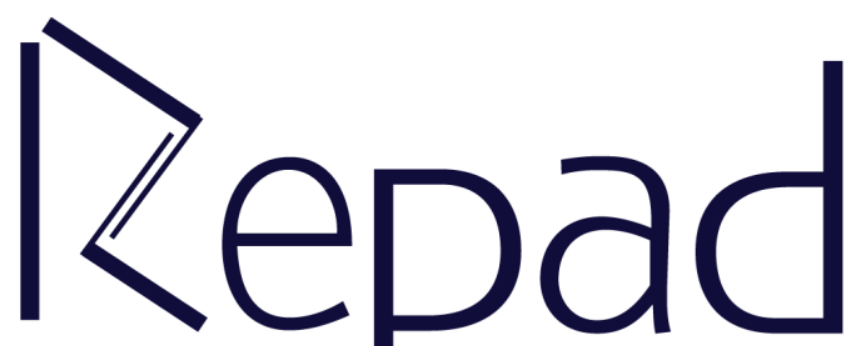

Revista Estudos e

Pesquisas em Administração 


\title{
AVALIAÇÃO DA SATISFAÇÃO SOB A ÓTICA DO CONSUMIDOR: Um estudo no varejo
}

\author{
Cláudio Chiusoli \\ http://orcid.org/0000-0002-7844-3632 \\ Universidade Estadual do Centro Oeste \\ Guarapuava, Paraná, Brasil \\ Elcio Vitor Kolodi \\ https://orcid.org/0000-0001-8864-0384 \\ Universidade Estadual do Centro Oeste \\ Pitanga, Paraná, Brasil \\ Nome Franciele Ladislau \\ https://orcid.org/0000-0002-6939-1770 \\ Universidade Estadual do Centro Oeste \\ Pitanga, Paraná, Brasil \\ Jaqueline Aparecida Egler \\ https://orcid.org/0000-0002-2760-0861 \\ Universidade Estadual do Centro Oeste \\ Pitanga, Paraná, Brasil \\ Josenilda Morais \\ https://orcid.org/0000-0002-2807-4787 \\ Universidade Estadual do Centro Oeste \\ Pitanga, Paraná, Brasil
}

\begin{abstract}
RESUMO
A chave para conquistar e manter clientes é criar na mente das pessoas uma experiência de satisfação. A satisfação é o sentimento de prazer ou desapontamento resultante da comparação do desempenho esperado sobre determinado serviço ou produto em relação às expectativas do consumidor. O objetivo do estudo é analisar a satisfação dos clientes em relação ao comércio de uma cidade do estado do Paraná. Este estudo foi realizado por meio de uma pesquisa bibliográfica e quantitativa, conforme a natureza das variáveis da pesquisa. A amostragem foi não probabilística por conveniência. O levantamento de dados foi feito por meio de 120 questionários aplicados aos consumidores. Os resultados mostram que o comércio da cidade tem alguns fatores negativos, e outros positivos, onde os principais achados apontam que os higiene e limpeza das lojas recebem a melhor avaliação (de "ótimo/bom"), com $75,0 \%$, enquanto que o pós venda aparece com $23,8 \%$ (de "ótimo/bom").
\end{abstract}

Palavras-chave: Satisfação. Pré-venda. Consumidor. 


\title{
EVALUATION OF SATISFACTION FROM A CONSUMER OPTIC: A retail study
}

\begin{abstract}
The key to winning and retaining customers is to create a satisfying experience in people's minds. Satisfaction is the feeling of pleasure or disappointment that results from comparing the expected performance of a particular service or product against consumer expectations. The aim of the study is to analyze the satisfaction of customers in relation to commerce in a city in the state of Paraná. This study was conducted by means of a bibliographic research and the nature of the research variables is characterized as quantitative. Sampling was not probabilistic for convenience. Data were collected through 120 questionnaires applied to consumers. The results show that the city's trade has some negative and some positive factors, where the main findings indicate that the hygiene and cleanliness of the stores receive the best rating (of "great/good"), with 75,0\%, while the post sales appear with $23,8 \%$ (of "great/good").
\end{abstract}

Keyword: Satisfaction. Presale. Consumer.

Submetido: $13 / 12 / 2019$

Aceito: 30/01/2020

Publicado: 31/01/2020

\section{INTRODUÇÃO}

Este estudo avalia a satisfação dos consumidores em relação ao comércio de varejo de uma cidade do estado do Paraná.

O varejo é conhecido como uma gama de empresas que realizam negócios e que acrescentam valor aos produtos e serviços ofertados aos consumidores seja para uso pessoal ou familiar e que envolve além das operações de venda, aspectos relacionados as finanças, marketing, espaço geográfico entre outros aspectos (BRITO; VIEIRA; ESPARTEL, 2011).

É notável a competitividade presente no mercado, decorrente do grande número e capacidade dos concorrentes. E obter a satisfação dos clientes ganhou mais importância no contexto gerencial, uma vez que possibilita a conquista e fidelização de clientes. A satisfação do consumidor é, para as empresas, o único meio de obter e manter clientes, e constitui um objetivo imprescindível para as organizações (LEVITT, 1990).

A satisfação é um sentimento de prazer ou de desapontamento resultante da comparação do desempenho esperado pelo produto (ou resultado) em relação às expectativas da pessoa; ou seja, o consumidor compara o valor pago pelo produto e os benefícios adquiridos com o mesmo, sendo esta a equação que resultará na satisfação ou insatisfação do consumidor com o produto adquirido (KOTLER; KELLER, 2006).

Por isso a importância de verificar qual o impacto da atmosfera das lojas de varejo a respeito das percepções de qualidade dos produtos e serviços, além dos preços praticados aos consumidores, e a influência exercida sobre a percepção acarreta na intenção de retorno e recomendação de uma loja (ESPINOZA; D'ANGELO; LIBERALI, 2005).

Assim os estudos da gestão de preços, de variedade e da qualidade e variedade dos produtos ofertados e do atendimento dado aos clientes, tem recebido maior ênfase 
desde então quando se pensa nos atributos de uma loja do varejo e que possa gerar fidelização (LOPES et al., 2013).

Considerando essa questão, a justificativa da pesquisa se dá pelo fato de que, conforme argumento de Hoffmann e Bateson (2008), não se pode minimizar a importância da satisfação do cliente, de forma que esta precisa ser medida e definida por todas as empresas de serviços.

Assim, o conhecimento das percepções e reações dos clientes, relacionados aos negócios de uma determinada organização, podem aumentar muito as possibilidades de tomar melhores decisões empresariais (HAYES, 1992).

Segundo Corrêa e Gianesi (1996), não é possível gerenciar o que não se pode medir; portanto, o maior benefício de conhecer o grau de satisfação dos clientes é saber onde é possível melhorar, visto que esperar que os clientes reclamem é uma atitude ingênua.

Para Kotler e Keller (2006), é importante satisfazer os consumidores porque as vendas de uma organização decorrem de dois grupos: consumidores novos e consumidores leais, e pode custar dezesseis vezes mais trazer um novo consumidor ao mesmo nível de rentabilidade de um consumidor perdido.

Assim, a retenção do consumidor é mais importante do que sua atração; a chave para a retenção do consumidor é sua satisfação para que torne-se lealdade. Baseado na visão de Kotler e Keller (2006), as pesquisas de satisfação dos clientes devem ser realizadas com frequência, porque os valores dos clientes estão em constante mudança. Convém ressaltar que pesquisas de satisfação dos clientes trazem benefícios tanto para os gerentes, que saberão o que podem melhorar, quanto para os clientes, que poderão desfrutar de um produto com maior qualidade.

Diante do exposto, o problema norteador da pesquisa tem por finalidade saber qual a avaliação da população quanto a sua satisfação em relação ao comércio local de uma cidade do estado do Paraná?

O objetivo do estudo é analisar a satisfação dos clientes em relação ao comércio de uma cidade do estado do Paraná. Como objetivos específicos, buscou-se avaliar: i) em relação ao conforto e ao ambiente oferecido; ii) em relação ao produto, preço, promoção e pontos de vendas; iii) em relação à qualidade, educação e rapidez do atendimento dos vendedores.

\section{REFERENCIAL TEÓRICO}

Previamente, foi realizada uma revisão teórica com o objetivo de esclarecer o assunto que compõe a literatura referente ao comportamento do consumidor, à satisfação do consumidor e atendimento pós-venda.

\section{Comportamento do consumidor}

Conforme Solomon (2016), os gestores de marketing reconhecem que o comportamento do consumidor nada mais é do que um processo contínuo que não se restringe apenas ao momento da compra, mas também na pré-compra e pós-compra.

O análise do comportamento do consumidor permite que se compreenda a geração de valor para o consumidor, satisfazendo as suas necessidades e desejos. Entender essas necessidades e desejos ajuda a pensar no mercado segundo a ótica dos consumidores (PINHEIRO et al., 2011). 
Para efetuar uma compra, o consumidor reconhece que tem um desejo ou necessidade por um produto ou serviço e procura informações em relação a este, avalia as alternativas e decide a compra. Por fim, consome e faz uma avaliação se está satisfeito ou insatisfeito (LARENTIS, 2012).

Para serem bem sucedidas no mercado competitivo e ganhar confiança do consumidor é preciso superar a concorrência e gerar valor significativo na entrega compreendendo os reais desejos e necessidades dos consumidores (KOTLER; ARMSTRONG, 2014).

Garcia (2011) afirma que o cliente concretiza uma compra após a tomada de decisão com base no pensamento, comportamento e sentimento do que deseja comprar. Dessa forma, é de suma importância que a empresa entenda esses aspectos relacionados à decisão de compra do consumidor para que possa definir as estratégias de atuação no mercado.

De acordo com Las Casas (2010), alguns clientes valorizam, para compra, aspectos que outros não valorizam, como status, estilos de vida, mudanças no perfil e outros. À medida em que a sociedade muda, as necessidades individuais de cada pessoa também mudam. O comportamento do consumidor está ligado à satisfação das suas necessidades e desejos, por isso é necessária uma avaliação detalhada do comportamento das pessoas antes, durante e depois da compra (SOLOMON, 2016).

O consumo é influenciado diretamente por fatores como idade, nível de escolaridade, nível de renda, gostos e preferências, dentre outros fatores. A partir do conhecimento de tais fatores é possível que as empresas tracem estratégias para a segmentação dos mercados e realizem uma análise do comportamento do consumidor em determinados nichos de mercado. Dessa forma, a partir da análise do mercado e das características de consumo dos clientes, é possível que as organizações desenvolvam novos produtos e serviços, condizentes às necessidades de cada tipo de consumidor, ou a cada grupo de consumo (LAS CASAS, 2010).

\section{Satisfação do consumidor}

Uma empresa só existe por causa dos seus compradores. Atendê-lo com propriedade, torna-se cada vez mais necessário para as organizações. A satisfação é capaz de levar a fidelização do consumidor, tornando-os parceiros nos negócios (COSTA; SANTANA; TRIGO, 2015).

Quando um consumidor aborrecido no processo de troca, repassa sua insatisfação para outras pessoas mais próximas, e hoje, a lealdade e confiança do cliente são essenciais para as empresas se manterem no seu negócios, o que realmente faz a diferença, pois quando as expectativas dos consumidores são atendidas a partir da compra ou consumo do produto, o resultado é a lealdade (LARA; SPINOZA, 2004).

A decisão de compra é do cliente, pois se a empresa não atender suas necessidades certamente terá concorrentes que fará (COSTA; SANTANA; TRIGO, 2015).

Existem três elementos característicos da satisfação; o primeiro elemento diz respeito que a satisfação denota um estado de natureza psicológica, que sugere um julgamento baseado na experiência decorrente de uma percepção racional, juntamente com os elementos emocionais. O segundo é que a satisfação se origina de uma situação de consumo, ou seja, surge de uma avaliação após a compra. O terceiro é que a satisfação detém uma característica relativa, uma vez que deriva de um processo comparativo entre 
a experiência de consumo subjetiva, vivida pelo consumidor, e uma base referencial anterior à compra (DANTAS, 2014).

Para Bezerra (2013), ter um cliente satisfeito não é tarefa fácil, pois o que é agrada uma pessoa pode não ser do agrado para outra. Pois cada pessoa possui características, opinião e gosto, diferente umas das outras, com isso é difícil conseguir satisfazer a totalidade dos clientes, mas é necessário haver um grande de esforço para alcançar a satisfação esperada pelo consumidor.

Conforme Kotler e Armstrong (2014), deter a atenção dos clientes não é uma tarefa fácil, uma vez que, os clientes têm à acesso a uma variedade maior de produtos, serviços, marcas, preços e fornecedores.

Segundo Costa, Santana e Trigo (2015), a organização deve se comprometer com o cliente, oferecendo um bom atendimento, fazendo-o se sentir importante para empresa, de modo a satisfazê-lo, pois assim, é possível conquistar e fidelizar esse cliente. Para satisfazer os clientes, é preciso conhecer o que é importante para eles, para focar nesses aspectos nos produtos uma vez que esses trarão maior satisfação.

Ainda segundo os mesmos autores, ao conhecer as necessidades e expectativas dos clientes, a organização pode determinar se está atendendo adequadamente, tomando essas informações para melhorar ou manter determinados aspectos. Além disso, as empresas precisam surpreender os clientes, indo além de suas expectativas.

A organização que toma decisões voltadas a atingir ou superar as expectativas dos clientes já estão a um passo à frente das concorrentes para sobreviver no mercado, pois, um cliente satisfeito além de voltar a consumir os produtos da empresa estimula a vinda de outros consumidores. E para que haja diferenciação nos serviços o desafio dos gestores é focar nas atividades que de fato atendam ou superem as expectativas dos clientes (ZACHARIAS; FIGUEIREDO; DE ALMEIDA, 2008).

\section{Atendimento pós-venda}

O pós-venda é um serviço oferecido após a realização da compra do produto ou serviço. Logo após a aquisição do produto ou serviço, se o cliente identificar algum aspecto estranho, ou caso ouça informações favoráveis de outros produtos ou serviços de outro estabelecimento, ficará atento às informações que apoiem sua decisão. Daí a importância do marketing de relacionamento que teve seu reconhecimento nas atividades de marketing no início dos a partir da década de 1990, como proposta de fidelização (CAMARGO, 2018).

A satisfação do cliente após a compra é muito importante, visto que influenciará seu comportamento subsequente. A fidelização do cliente está intimamente ligada à relação que a empresa mantém com ele após fechar uma venda de um produto ou serviço. O consumidor deseja apenas satisfazer uma necessidade e, para que ele volte, deve haver essa relação pós-venda. O comprador deseja, ao escolher por determinada empresa, que ela se manifeste interessada por ele, independentemente se a venda ocorrer ou não (COSTA; SANTANA; TRIGO, 2015).

É necessário que as empresas tenham um programa de pós-venda que estimule a fidelização, procurando torná-la distinta das concorrentes. É preciso ouvir os clientes, suas sugestões e reclamações, e exercer o marketing de relacionamento com os clientes (RODRIGUES; SILVA; ANDRADE, 2011), sendo um poderoso aliado comercial entre as organizações e os clientes (ARAUJO; LOPES, 2019). 
Segundo Sobrinho (2005), o cliente de hoje não busca mais aquela empresa que faz o melhor trabalho da região, ele busca a empresa que entrega, junto ao serviço solicitado, um brinde chamado satisfação. Dessa forma, os clientes esperam que o serviço pós-venda seja um atributo do produto tanto quanto a qualidade, o design, seu rendimento e o preço.

Para Berro (2010), o serviço de pós-venda não é somente um diferencial competitivo, mas também uma ferramenta vital no processo de fidelização do cliente, uma vez que, as instituições podem aumentar a base de clientes e mantê-los. Tal afirmação a seguir justifica a importância do atendimento pós-venda como parte da estratégia de fidelização de cliente.

E, conforme exposto por Castro (2012), ao se utilizar de metodologias e técnicas adequadas, um bom programa de estudo da satisfação dos clientes permite: avaliar o grau de satisfação dos clientes; avaliar o desempenho da empresa em relação aos seus principais concorrentes; compreender os aspectos de maior impacto para a satisfação dos clientes; avaliar a sintonia entre a direção e a expectativa dos clientes; definir estratégia de melhoria de qualidade a partir dos pontos fortes e dos pontos a desenvolver; otimizar os investimentos a partir da definição precisa de estratégia de qualidade.

Nas últimas décadas, muitas organizações passaram a perceber que os colaboradores são seus ativos mais importantes. Isso é mais palpável no atendimento ao cliente. São os colaboradores que estão na linha de frente, cara a cara com o consumidor. E mesmo que não estejam em contato direto, são eles que controlam as operações e processos pelos quais o atendimento é realizado (EISNER, 2011).

\section{PROCEDIMENTO METODOLÓGICOS}

Este estudo foi realizado por meio de uma pesquisa empírica e bibliográfica. A pesquisa empírica, segundo Demo (2000), se dedica ao experimento e ao tratamento baseados na realidade, cria e analisa dados. Já a pesquisa bibliográfica, de acordo com Gil (2017), é elaborada com base em materiais já publicados sobre determinado tema de pesquisa. Deste modo, foram utilizadas fontes de natureza bibliográfica, tais como: livros, artigos científicos e outras publicações, objetivando do tema objeto do estudo.

Assim, desdobra-se mais detalhadamente sua confecção diante de 9 quesitos explicativos que seguem: i) Quanto à natureza das variáveis e objetivos; ii) Quanto à população e à unidade de observação; iii) Quanto às variáveis e escalas utilizadas; vi) Quanto à técnica de amostragem; v) Quanto à forma da coleta dos dados; vi) Quanto à forma da abordagem; vii) Quanto à procedência dos dados; viii) Quanto ao recorte; e ix) Quanto à técnica estatística.

Quanto à natureza das variáveis, a pesquisa foi caracterizada como quantitativa, a qual, segundo Fonseca (2002), se centra na objetividade. Influenciada pelo positivismo, considera que a realidade só pode ser compreendida com base na análise de dados brutos, recolhidos com o auxílio de instrumentos padronizados e neutros. A pesquisa quantitativa recorre à linguagem matemática para descrever as causas de um fenômeno, as relações entre as variáveis.

Quanto às variáveis, foram utilizadas 14 questões, sendo 4 perfis (gênero, faixa etária, escolaridade e ocupação atual). As questões abordadas avaliavam quesitos sobre: o comportamento do vendedor (se ele é cordial, educado, se atende com qualidade e rapidez) e sobre como é o comércio (se tem higiene/limpeza, os preços praticados, 
promoções oferecidas, qualidade e variedade dos produtos, decoração e beleza das vitrines e o contato da empresa após a compra).

Quanto à escala utilizada, foi a ordinal, que define a posição de relação de objetos ou indivíduos sobre uma característica, mas não tem suposições quanto a distância entre as posições (GIL, 2017).

Quanto aos objetivos, esta pesquisa foi classificada como descritiva, o qual, exige do investigador uma série de informações sobre o que se deseja pesquisar, uma vez que, esse tipo de estudo pretende descrever os fatos e fenômenos de determinada realidade (TRIVIÑOS, 1987).

Quanto à população e unidade de observação, trata-se de uma cidade do interior do Paraná e foi definido de que o participante do estudo deveria ser o consumidor que circulava no comércio e estava fazendo algum tipo de compra. E por se tratar de uma cidade pequeno porte em torno de cerca de 30 mil habitantes, optou-se por fazer o levantamento em um final de semana no qual as pessoas teriam um maior tempo para ir ao comércio, além do que, muitos moram na zona rural.

Quanto à técnica de amostragem, foi definida como não probabilística por conveniência, e por cotas quanto ao gênero, na qual, segundo Gil (2017), o pesquisador selecionava os elementos a que tem acesso com maior facilidade, considerando que estes possam, de alguma forma, retratar a realidade dos consumidores da cidade.

No total foram entrevistados 120 consumidores, o que se torna necessário registrar que devido a técnica de amostragem utilizada, não se deve realizar inferência dos resultados para toda a população da cidade.

Quanto à forma da abordagem, a pesquisa foi realizada in loco, e os questionários foram aplicados pessoalmente junto ao consumidor que frequentava o comércio de rua.

Quanto à procedência dos dados, trata-se de dados primários, que são aqueles que não foram antes coletados, estando ainda com os pesquisadores, e que são coletados com o propósito de atender às necessidades específicas da pesquisa em andamento (MATTAR, 2001).

Quanto ao recorte da pesquisa, trata-se de um estudo transversal, no qual a coleta dos dados ocorreu em um só momento, pretendendo descrever e analisar o estado de uma ou várias variáveis em um dado momento (SAMPIERI et al., 1991).

Quanto à técnica estatística, a análise dos dados consistiu em análises univariadas e bivariadas com base em frequências absolutas e relativas. As medidas de associação foram testadas por meio do teste não paramétrico, o Qui-Quadrado (SIEGEL; CASTELLAN, 2017), cuja hipótese da pesquisa (H0) formulada é: Não há diferença significativa na avaliação do comércio em relação às variáveis pesquisadas segmentadas por gênero, faixa etária, escolaridade e ocupação atual.

\section{ANÁLISE E APRESENTAÇÃO DOS DADOS}

A pesquisa foi aplicada junto aos consumidores de uma cidade do estado do Paraná, onde responderam um questionário com questões relacionadas à satisfação dos clientes em relação ao comércio da cidade.

Por meio dos Quadros 1 a 3 apresenta-se o perfil dos entrevistados. As análises realizadas são referente aos Quadros 4 a 14 que estão segmentados pelo perfil dos entrevistados: gênero (feminino e masculino), faixa etária (até 20 anos, de 21 a 30 anos e acima de 30 anos), escolaridade (fundamental/médio e superior) e o enquadramento atual quanto a ocupação (estudo, trabalho e estudo/trabalho). 
O Quadro 15 finaliza com o resumo da pesquisa e o Quadro 16 apresenta o teste estatístico não paramétrico Qui-Quadrado para verificar se há divergências de opiniões em relação às categorias estudadas.

\section{Perfil dos entrevistados}

O Quadro 1 apresenta o perfil dos entrevistados quanto ao gênero. Os entrevistados foram estratificados referente a este aspecto, sendo 50\% masculino e 50\% feminino. Observa-se que os participantes de maior faixa etária, acima dos 30 anos, em maior proporção do sexo masculino $(57,1 \%)$. Entre os entrevistados com curso superior, predominam as mulheres $(59,4 \%)$ e da mesma forma entre aqueles que declaram que somente estudam os entrevistados feminino representam $69,2 \%$.

\begin{tabular}{|c|c|c|c|c|c|c|c|c|c|}
\multicolumn{10}{|c|}{ Quadro 1. Gênero versus faixa etária, escolaridade e ocupação } \\
\hline & $\begin{array}{c}\text { Até } \\
\mathbf{2 0}\end{array}$ & $\mathbf{2 1 / 3 0}$ & $\mathbf{3 0 +}$ & Fund/Médio & Sup. & Estudo & Trabalho & Estudo/trab. & Total \\
\hline Feminino & $55,6 \%$ & $51,0 \%$ & $42,9 \%$ & $39,3 \%$ & $59,4 \%$ & $69,2 \%$ & $42,6 \%$ & $51,7 \%$ & $50,0 \%$ \\
\hline Masculino & $44,4 \%$ & $49,0 \%$ & $57,1 \%$ & $60,7 \%$ & $40,6 \%$ & $30,8 \%$ & $57,4 \%$ & $48,3 \%$ & $50,0 \%$ \\
\hline Total & $100 \%$ & $100 \%$ & $100 \%$ & $100 \%$ & $100 \%$ & $100 \%$ & $100 \%$ & $100 \%$ & $100 \%$ \\
\hline
\end{tabular}

Fonte. Dados da pesquisa (2019)

O Quadro 2 apresenta o perfil dos entrevistados quanto à faixa etária. Por meio dele é possível perceber que os participantes do sexo masculino $(33,3 \%)$ em proporção são mais velhos que aqueles do sexo feminino (25\%), acima de 30 anos; além disso, entre o que somente estudam, predominam os mais jovens, com até 20 anos $(76,9 \%)$, enquanto os que se declararam que somente trabalham predomina os entrevistados com mais de 30 $\operatorname{anos}(57,4 \%)$.

Quadro 2. Faixa etária versus sexo, escolaridade e ocupação

\begin{tabular}{|c|c|c|c|c|c|c|c|c|}
\hline & Fem. & Masc. & Fund/Médio & Sup. & Estudo & Trabalho & Estudo/trab. & Total \\
\hline Até 20 anos & $33,3 \%$ & $26,7 \%$ & $23,2 \%$ & $35,9 \%$ & $76,9 \%$ & $4,3 \%$ & $40,0 \%$ & $30,0 \%$ \\
\hline $21 / 30$ anos & $41,7 \%$ & $40,0 \%$ & $39,3 \%$ & $42,2 \%$ & $23,1 \%$ & $38,3 \%$ & $46,7 \%$ & $40,8 \%$ \\
\hline $30+$ & $25,0 \%$ & $33,3 \%$ & $37,5 \%$ & $21,9 \%$ & $0,0 \%$ & $57,4 \%$ & $13,3 \%$ & $29,2 \%$ \\
\hline Total & $100 \%$ & $100 \%$ & $100 \%$ & $100 \%$ & $100 \%$ & $100 \%$ & $100 \%$ & $100 \%$ \\
\hline
\end{tabular}

Fonte. Dados da pesquisa (2019)

O Quadro 3 apresenta o perfil dos entrevistados quanto à escolaridade; através dele nota-se que os participantes do sexo feminino, em sua maioria, têm ensino superior $(63,3 \%)$, enquanto os do sexo masculino têm ensino fundamental ou médio $(56,7 \%)$. Além disso, os participantes mais jovens, até 20 anos, em comparação possuem curso superior $(63,9 \%)$, enquanto os entrevistados com idade acima de 30 anos, predomina sua escolaridade de ensino fundamental e médio $(60 \%)$.

Quadro 3. Escolaridade versus sexo, faixa etária e ocupação

\begin{tabular}{|c|c|c|c|c|c|c|c|c|c|}
\hline & Fem. & Masc. & Até 20 & $\mathbf{2 1 / 3 0}$ & 30+ & Estudo & Trabalho & Estudo/trab. & Total \\
\hline Fund./Médio & $36,7 \%$ & $56,7 \%$ & $36,1 \%$ & $44,9 \%$ & $60,0 \%$ & $46,2 \%$ & $66,0 \%$ & $31,7 \%$ & $46,7 \%$ \\
\hline Superior & $63,3 \%$ & $43,3 \%$ & $63,9 \%$ & $55,1 \%$ & $40,0 \%$ & $53,8 \%$ & $34,0 \%$ & $68,3 \%$ & $53,3 \%$ \\
\hline Total & $100 \%$ & $100 \%$ & $100 \%$ & $100 \%$ & $100 \%$ & $100 \%$ & $100 \%$ & $100 \%$ & $100 \%$ \\
\hline
\end{tabular}

Fonte. Dados da pesquisa (2019) 
O Quadro 4 apresenta o perfil dos respondentes quanto à ocupação atual, percebese que, em ambos os sexos, a maioria trabalha e estuda (51,7\% entre as mulheres e 48,3\% entre os homens), também que a maioria com até 20 anos trabalha e estuda (66,7\%); dos 21 aos 30 anos também $(57,1 \%)$, e acima dos 30 somente trabalha $(77,1 \%)$. Entre os entrevistados quanto a escolaridade, aqueles que possuem nível fundamental e médio, $55 \%$ apenas trabalha; e com nível superior, $64 \%$ trabalha e estuda.

Quadro 4. Ocupação atual versus sexo, faixa etária e escolaridade

\begin{tabular}{|c|c|c|c|c|c|c|c|c|}
\hline & Fem. & Masc. & Até 20 & $\mathbf{2 1 / 3 0}$ & $\mathbf{3 0 +}$ & Fund/Médio & Sup. & Total \\
\hline Trabalho e estudo & $51,7 \%$ & $48,3 \%$ & $66,7 \%$ & $57,1 \%$ & $22,9 \%$ & $33,9 \%$ & $64,1 \%$ & $50,0 \%$ \\
\hline Apenas trabalho & $33,3 \%$ & $45,0 \%$ & $5,6 \%$ & $36,7 \%$ & $77,1 \%$ & $55,4 \%$ & $25,0 \%$ & $39,2 \%$ \\
\hline Apenas estudo & $15,0 \%$ & $6,7 \%$ & $27,8 \%$ & $6,1 \%$ & $0,0 \%$ & $10,7 \%$ & $10,9 \%$ & $10,8 \%$ \\
\hline Total & $100 \%$ & $100 \%$ & $100 \%$ & $100 \%$ & $100 \%$ & $100 \%$ & $100 \%$ & $100 \%$ \\
\hline
\end{tabular}

Fonte. Dados da pesquisa (2019)

\section{DISCUSSÃO DOS RESULTADOS}

O Quadro 5 tem por objetivo apresentar a avaliação dos consumidores referente à educação e cordialidade dos vendedores no comércio da cidade. Percebe-se que dentre os consumidores, $55,8 \%$ avaliam como ótimo ou bom, 33,3\% avaliam como regular, e 10,8\% avaliam como Ruim ou Péssimo. Dessa forma, chegou-se a um indicador de $44,1 \%$ de "regular/ruim/péssimo", uma vez que se destaca os consumidores de faixa etária entre 21 a 30 anos que avaliam com menor satisfação (49\%) e as mulheres (46,7\%). Diante dos números obtidos, Cabe então aos gestores atentar para essa variável, pois a qualidade no atendimento é um aspecto fundamental, levado muito a sério pelas empresas privadas, onde a educação e a cordialidade, a maneira com a qual são tratados os clientes pode ser determinante de sucesso ou insucesso da organização (DA SILVA MELO; DA SILVA; QUEVEDO, 2016).

\begin{tabular}{|c|c|c|c|c|c|c|c|c|c|c|c|}
\hline \multicolumn{10}{|c|}{ Quadro 5. Educação e cordialidade dos vendedores } \\
\hline & Fem. & Masc. & Até 20 & $\mathbf{2 1 / 3 0}$ & $\mathbf{3 0 +}$ & $\begin{array}{c}\text { Fund } \\
\text { /Médio }\end{array}$ & Sup. & Estudo & Trabalho & $\begin{array}{c}\text { Estudo } \\
\text { /trab. }\end{array}$ & Total \\
\hline $\begin{array}{c}\text { Ótimo } \\
\text { /Bom }\end{array}$ & $53,3 \%$ & $58,3 \%$ & $55,6 \%$ & $51,0 \%$ & $62,9 \%$ & $58,9 \%$ & $53,1 \%$ & $61,5 \%$ & $53,2 \%$ & $56,7 \%$ & $55,8 \%$ \\
\hline Regular & $31,7 \%$ & $35,0 \%$ & $38,9 \%$ & $30,6 \%$ & $31,4 \%$ & $35,7 \%$ & $31,3 \%$ & $30,8 \%$ & $34,0 \%$ & $33,3 \%$ & $33,3 \%$ \\
\hline $\begin{array}{c}\text { Ruim } \\
\text { /Péssimo }\end{array}$ & $15,0 \%$ & $6,7 \%$ & $5,6 \%$ & $18,4 \%$ & $5,7 \%$ & $5,4 \%$ & $15,6 \%$ & $7,7 \%$ & $12,8 \%$ & $10,0 \%$ & $10,8 \%$ \\
\hline Total & $100 \%$ & $100 \%$ & $100 \%$ & $100 \%$ & $100 \%$ & $100 \%$ & $100 \%$ & $100 \%$ & $100 \%$ & $100 \%$ & $100 \%$ \\
\hline
\end{tabular}

Fonte. Dados da pesquisa (2019)

O Quadro 6 apresenta a avaliação dos consumidores quanto ao atendimento dos vendedores. Percebe-se que $54,2 \%$ dos entrevistados consideram o atendimento como ótimo/bom, 37,5\% consideram como regular e 8,3\% consideram ruim/péssimo. Dessa forma, importante destacar quando o consumidor é bem atendido pela empresa, cria uma espécie de padrão que será referência todas as vezes que retornar a empresa, e ainda comentará a outros amigos a se tornarem clientes (COSTA; SANTANA; TRIGO, 2015). 


\begin{tabular}{|c|c|c|c|c|c|c|c|c|c|c|c|}
\hline \multicolumn{2}{|c|}{ Quadro 6. Qualidade do atendimento dos vendedores } & & & & & & & & & & \\
\hline & Fem. & Masc. & Até 20 & 21/30 & 30+ & $\begin{array}{l}\text { Fund } \\
\text { /Médio }\end{array}$ & Sup. & Estudo & Trabalho & $\begin{array}{c}\text { Estudo } \\
\text { /trab. }\end{array}$ & Total \\
\hline $\begin{array}{l}\text { Ótimo } \\
\text { /Bom }\end{array}$ & $53,3 \%$ & $55,0 \%$ & $58,3 \%$ & $46,9 \%$ & $60,0 \%$ & $62,5 \%$ & $46,9 \%$ & $53,8 \%$ & $44,7 \%$ & $61,7 \%$ & $54,2 \%$ \\
\hline Regular & $33,3 \%$ & $41,7 \%$ & $36,1 \%$ & $38,8 \%$ & $37,1 \%$ & $32,1 \%$ & $42,2 \%$ & $30,8 \%$ & $46,8 \%$ & $31,7 \%$ & $37,5 \%$ \\
\hline $\begin{array}{c}\text { Ruim } \\
\text { /Péssimo }\end{array}$ & $13,3 \%$ & $3,3 \%$ & $5,6 \%$ & $14,3 \%$ & $2,9 \%$ & $5,4 \%$ & $10,9 \%$ & $15,4 \%$ & $8,5 \%$ & $6,7 \%$ & $8,3 \%$ \\
\hline Total & $100 \%$ & $100 \%$ & $100 \%$ & $100 \%$ & $100 \%$ & $100 \%$ & $100 \%$ & $100 \%$ & $100 \%$ & $100 \%$ & $100 \%$ \\
\hline
\end{tabular}

Fonte. Dados da pesquisa (2019)

O Quadro 7 apresenta a avaliação dos clientes quanto à rapidez no atendimento dos vendedores. Sendo que $45 \%$ dos entrevistados consideram a rapidez como ótima/boa, $46,7 \%$ consideram regular, e $8,3 \%$ consideram ruim/péssimo. O fato de $46,7 \%$ dos entrevistados considerarem regular é um sinal de alerta para os empresários. Estes devem estar atentos a esses sinais, capacitando seus funcionários para serem mais ágeis e não deixarem o cliente esperando, por meio de treinamentos que possa aperfeiçoar o atendimento (EISNER, 2011)

Quadro 7. Rapidez no atendimento dos vendedores

\begin{tabular}{|c|c|c|c|c|c|c|c|c|c|c|c|}
\hline & Fem. & Masc. & $\begin{array}{c}\text { Até } \\
\mathbf{2 0}\end{array}$ & $\mathbf{2 1 / 3 0}$ & $\mathbf{3 0 +}$ & $\begin{array}{c}\text { Fund } \\
\text { /Médio }\end{array}$ & Sup. & Estudo & Trabalho & $\begin{array}{c}\text { Estudo } \\
\text { /trab. }\end{array}$ & Total \\
\hline $\begin{array}{c}\text { Ótimo } \\
\text { /Bom }\end{array}$ & $51,7 \%$ & $38,3 \%$ & $50,0 \%$ & $49,0 \%$ & $34,3 \%$ & $48,2 \%$ & $42,2 \%$ & $46,2 \%$ & $36,2 \%$ & $51,7 \%$ & $45,0 \%$ \\
\hline Regular & $38,3 \%$ & $55,0 \%$ & $47,2 \%$ & $34,7 \%$ & $62,9 \%$ & $44,6 \%$ & $48,4 \%$ & $53,8 \%$ & $55,3 \%$ & $38,3 \%$ & $46,7 \%$ \\
\hline $\begin{array}{c}\text { Ruim } \\
\text { /Péssimo }\end{array}$ & $10,0 \%$ & $6,7 \%$ & $2,8 \%$ & $16,3 \%$ & $2,9 \%$ & $7,1 \%$ & $9,4 \%$ & $0,0 \%$ & $8,5 \%$ & $10,0 \%$ & $8,3 \%$ \\
\hline Total & $100 \%$ & $100 \%$ & $100 \%$ & $100 \%$ & $100 \%$ & $100 \%$ & $100 \%$ & $100 \%$ & $100 \%$ & $100 \%$ & $100 \%$ \\
\hline
\end{tabular}

Fonte. Dados da pesquisa (2019)

O Quadro 8 busca explicitar a opinião dos consumidores quanto a higiene e limpeza das lojas. O entrevistados com $75 \%$ responderam ótimo/bom; $21 \%$ disseram que é regular; e apenas 3,3\% consideram ruim/péssimo. Aliás, essa variável foi o quesito de melhor avaliação entre todas e chega a $83,3 \%$ de ótimo/bom entre os entrevistados até 20 anos e $80 \%$ para aquele que tem acima de 30 anos. Considerando esse indicador que foi positivo, ressalta a importância do lojista se ater ao impacto que a atmosfera das lojas de varejo repassa ao consumidor, pois sua percepção acarreta na intenção de retorno e recomendação de uma loja (LARA; ESPINOZA, 2004).

\begin{tabular}{|c|c|c|c|c|c|c|c|c|c|c|c|}
\multicolumn{10}{|c|}{ Quadro 8. Higiene/limpeza das lojas } \\
\hline & Fem. & Masc. & Até 20 & $\mathbf{2 1 / 3 0}$ & $\mathbf{3 0 +}$ & $\begin{array}{c}\text { Fund } \\
\text { /Médio }\end{array}$ & Sup. & Estudo & Trabalho & $\begin{array}{c}\text { Estudo } \\
\text { /trab. }\end{array}$ & Total \\
\hline $\begin{array}{c}\text { Ótimo } \\
\text { /Bom }\end{array}$ & $76,7 \%$ & $73,3 \%$ & $83,3 \%$ & $65,3 \%$ & $80,0 \%$ & $73,2 \%$ & $76,6 \%$ & $69,2 \%$ & $72,3 \%$ & $78,3 \%$ & $75,0 \%$ \\
\hline Regular & $21,7 \%$ & $21,7 \%$ & $16,7 \%$ & $30,6 \%$ & $14,3 \%$ & $25,0 \%$ & $18,8 \%$ & $30,8 \%$ & $23,4 \%$ & $18,3 \%$ & $21,7 \%$ \\
\hline $\begin{array}{c}\text { Ruim } \\
\text { /Péssimo }\end{array}$ & $1,7 \%$ & $5,0 \%$ & $0,0 \%$ & $4,1 \%$ & $5,7 \%$ & $1,8 \%$ & $4,7 \%$ & $0,0 \%$ & $4,3 \%$ & $3,3 \%$ & $3,3 \%$ \\
\hline Total & $100 \%$ & $100 \%$ & $100 \%$ & $100 \%$ & $100 \%$ & $100 \%$ & $100 \%$ & $100 \%$ & $100 \%$ & $100 \%$ & $100 \%$ \\
\hline
\end{tabular}

Fonte. Dados da pesquisa (2019)

O Quadro 9 apresenta a opinião dos consumidores quanto ao preço praticado o comércio. Nesse quesito observa-se que apenas 26,7\% dos entrevistados consideram ótimo/bom; 43,3\% consideram regular; e já os que consideram ruim ou péssimo são $30 \%$. 
O que demonstra que 73,3\% citam "regular/ruim/péssimo" o que indica que a percepção em relação aos preços praticados são altos e não devem agradam a população.

Logo, muito provavelmente por ser uma cidade menor o consumidor tem referência de preços de outros grandes centros de compras no qual a população saem para fazer suas compras. Ou ainda, com a expansão da internet e o surgimento dos dispositivos móveis, a maneira como os consumidores se relacionam mudou e a vezes dependendo do produtos compram pela internet (SAUSEN et al., 2018). Ademais, corroborado por Kotler e Armstrong (2014), o consumidor é influenciado pelas estratégias de preço quando está avaliando alternativas e, geralmente, vão dar preferências a produtos mais baratos.

Quadro 9. Preços praticados no comércio local

\begin{tabular}{|c|c|c|c|c|c|c|c|c|c|c|c|}
\hline & Fem. & Masc. & Até 20 & $\mathbf{2 1 / 3 0}$ & $\mathbf{3 0}+$ & $\begin{array}{c}\text { Fund/ } \\
\text { Médio }\end{array}$ & Sup. & Estudo & Trabalho & $\begin{array}{c}\text { Estudo/ } \\
\text { trab. }\end{array}$ & Total \\
\hline $\begin{array}{c}\text { Ótimo } \\
\text { /Bom }\end{array}$ & $26,7 \%$ & $26,7 \%$ & $38,9 \%$ & $18,4 \%$ & $25,7 \%$ & $26,8 \%$ & $26,6 \%$ & $38,5 \%$ & $23,4 \%$ & $26,7 \%$ & $26,7 \%$ \\
\hline Regular & $50,0 \%$ & $36,7 \%$ & $44,4 \%$ & $38,8 \%$ & $48,6 \%$ & $41,1 \%$ & $45,3 \%$ & $23,1 \%$ & $34,0 \%$ & $55,0 \%$ & $43,3 \%$ \\
\hline $\begin{array}{c}\text { Ruim } \\
\text { /Péssimo }\end{array}$ & $23,3 \%$ & $36,7 \%$ & $16,7 \%$ & $42,9 \%$ & $25,7 \%$ & $32,1 \%$ & $28,1 \%$ & $38,5 \%$ & $42,6 \%$ & $18,3 \%$ & $30,0 \%$ \\
\hline Total & $100 \%$ & $100 \%$ & $100 \%$ & $100 \%$ & $100 \%$ & $100 \%$ & $100 \%$ & $100 \%$ & $100 \%$ & $100 \%$ & $100 \%$ \\
\hline
\end{tabular}

Fonte. Dados da pesquisa (2019)

O Quadro 10 mostra a percepção dos consumidores quanto às promoções oferecidas pelo comércio. Nota-se que em ambos os sexos a maioria avalia como ótimo/bom (43,3\%). Porém, entre as mulheres avalia melhor, com 48,3\%, quando comparado com 38,3\% dos homens. Quanto à faixa etária, as pessoas mais jovens, até 20 anos, avaliam melhor esse quesito, com $50 \%$. Dessa forma, a ação do varejista por meio de promoção de vendas pode tornar um fator de destaque para a empresa considerando que é uma atividade de marketing importante conquistar o cliente (DA SILVA, 2016).

Quadro 10. Promoções oferecidas pelo comércio

\begin{tabular}{|c|c|c|c|c|c|c|c|c|c|c|c|}
\hline & Fem. & Masc. & Até 20 & $\mathbf{2 1 / 3 0}$ & $\mathbf{3 0 +}$ & $\begin{array}{c}\text { Fund/ } \\
\text { Médio }\end{array}$ & Sup. & Estudo & Trabalho & $\begin{array}{c}\text { Estudo } \\
\text { /trab. }\end{array}$ & Total \\
\hline $\begin{array}{c}\text { Ótimo } \\
\text { /Bom }\end{array}$ & $48,3 \%$ & $38,3 \%$ & $50,0 \%$ & $36,7 \%$ & $45,7 \%$ & $46,4 \%$ & $40,6 \%$ & $53,8 \%$ & $38,3 \%$ & $45,0 \%$ & $43,3 \%$ \\
\hline Regular & $38,3 \%$ & $41,7 \%$ & $38,9 \%$ & $42,9 \%$ & $37,1 \%$ & $42,9 \%$ & $37,5 \%$ & $30,8 \%$ & $42,6 \%$ & $40,0 \%$ & $40,0 \%$ \\
\hline $\begin{array}{c}\text { Ruim } \\
\text { /Péssimo }\end{array}$ & $13,3 \%$ & $20,0 \%$ & $11,1 \%$ & $20,4 \%$ & $17,1 \%$ & $10,7 \%$ & $21,9 \%$ & $15,4 \%$ & $19,1 \%$ & $15,0 \%$ & $16,7 \%$ \\
\hline Total & $100 \%$ & $100 \%$ & $100 \%$ & $100 \%$ & $100 \%$ & $100 \%$ & $100 \%$ & $100 \%$ & $100 \%$ & $100 \%$ & $100 \%$ \\
\hline
\end{tabular}

Fonte. Dados da pesquisa (2019)

O Quadro 11 busca analisar o julgamento dos consumidores quanto à qualidade dos produtos oferecidos. Sobre esse quesito, mais da metade dos entrevistados consideram ótimo/bom, somando assim 58,3\% das respostas. Sendo que 33,3\% dizem ser regular, e apenas 8,3\% consideram ruim. Isso sugere que há uma preocupação do comércio sempre oferecer promoções e buscando uma melhoria nos preços, o que reforça, segundo Morais et al. (2018), que para satisfazer as necessidades dos consumidores, é preciso que os produtos ofertados por uma empresa apresentem boa qualidade e ainda $o$ gestor deve investir na qualificação de funcionários, na variedade de produtos/marcas, nos serviços de logística e no gerenciamento de reclamações/devolução de produtos. 
Quadro 11. Qualidade dos produtos oferecidos

\begin{tabular}{|c|c|c|c|c|c|c|c|c|c|c|c|}
\hline & Fem. & Masc. & Até 20 & $\mathbf{2 1 / 3 0}$ & $\mathbf{3 0 +}$ & $\begin{array}{c}\text { Fund/ } \\
\text { Médio }\end{array}$ & Sup. & Estudo & Trabalho & $\begin{array}{c}\text { Estudo } \\
\text { /trab. }\end{array}$ & Total \\
\hline $\begin{array}{c}\text { Ótimo } \\
\text { /Bom }\end{array}$ & $61,7 \%$ & $55,0 \%$ & $63,9 \%$ & $57,1 \%$ & $54,3 \%$ & $50,0 \%$ & $65,6 \%$ & $46,2 \%$ & $51,1 \%$ & $66,7 \%$ & $58,3 \%$ \\
\hline Regular & $28,3 \%$ & $38,3 \%$ & $30,6 \%$ & $34,7 \%$ & $34,3 \%$ & $39,3 \%$ & $28,1 \%$ & $38,5 \%$ & $40,4 \%$ & $26,7 \%$ & $33,3 \%$ \\
\hline $\begin{array}{c}\text { Ruim } \\
\text { /Péssimo }\end{array}$ & $10,0 \%$ & $6,7 \%$ & $5,6 \%$ & $8,2 \%$ & $11,4 \%$ & $10,7 \%$ & $6,3 \%$ & $15,4 \%$ & $8,5 \%$ & $6,7 \%$ & $8,3 \%$ \\
\hline Total & $100 \%$ & $100 \%$ & $100 \%$ & $100 \%$ & $100 \%$ & $100 \%$ & $100 \%$ & $100 \%$ & $100 \%$ & $100 \%$ & $100 \%$ \\
\hline
\end{tabular}

Fonte. Dados da pesquisa (2019)

O Quadro 12 aponta a opinião dos consumidores quanto à variedade de produtos na cidade, pelo qual percebe-se, com 43,3\%, avaliam como ótimo/bom, sendo julgamentos mais positivos entre o sexo feminino (46,7\%); pessoas com até 20 anos $(47,2 \%)$ e pessoas que trabalham e estudam $(48,3 \%)$; e quanto à escolaridade, os resultados são bastante próximos oscilando entre $40 \%$ a $43 \%$. Isso reforça o argumento de Kotler e Armstrong (2014), o consumidor de hoje busca constantemente informações devido a facilidade de acesso e o auxílio da internet que é muito grande, propiciando comparações dos diversos produtos e serviços oferecidos.

Quadro 12. Variedade de produtos na cidade

\begin{tabular}{|c|c|c|c|c|c|c|c|c|c|c|c|}
\hline & Fem. & Masc. & Até 20 & $\mathbf{2 1 / 3 0}$ & $\mathbf{3 0}+$ & $\begin{array}{c}\text { Fund/ } \\
\text { Médio }\end{array}$ & Sup. & Estudo & Trabalho & $\begin{array}{c}\text { Estudo } \\
\text { /trab. }\end{array}$ & Total \\
\hline $\begin{array}{c}\text { Ótimo } \\
\text { /Bom }\end{array}$ & $46,7 \%$ & $40,0 \%$ & $47,2 \%$ & $40,8 \%$ & $42,9 \%$ & $42,9 \%$ & $43,8 \%$ & $23,1 \%$ & $42,6 \%$ & $48,3 \%$ & $43,3 \%$ \\
\hline Regular & $26,7 \%$ & $38,3 \%$ & $36,1 \%$ & $28,6 \%$ & $34,3 \%$ & $32,1 \%$ & $32,8 \%$ & $76,9 \%$ & $29,8 \%$ & $25,0 \%$ & $32,5 \%$ \\
\hline $\begin{array}{c}\text { Ruim } \\
\text { /Péssimo }\end{array}$ & $26,7 \%$ & $21,7 \%$ & $16,7 \%$ & $30,6 \%$ & $22,9 \%$ & $25,0 \%$ & $23,4 \%$ & $0,0 \%$ & $27,7 \%$ & $26,7 \%$ & $24,2 \%$ \\
\hline Total & $100 \%$ & $100 \%$ & $100 \%$ & $100 \%$ & $100 \%$ & $100 \%$ & $100 \%$ & $100 \%$ & $100 \%$ & $100 \%$ & $100 \%$ \\
\hline
\end{tabular}

Fonte. Dados da pesquisa (2019)

O Quadro 13 tem o intuito de analisar a percepção dos clientes quanto à vitrine/fachada como decoração e beleza das lojas; nele é visível que o sexo feminino tem uma avaliação melhor com $60 \%$ de ótimo/bom.

Quadro 13. Vitrines/fachadas como decoração e beleza

\begin{tabular}{|c|c|c|c|c|c|c|c|c|c|c|c|}
\hline & Fem. & Masc. & Até 20 & $\mathbf{2 1 / 3 0}$ & $\mathbf{3 0 +}$ & $\begin{array}{c}\text { Fund/ } \\
\text { Médio }\end{array}$ & Sup. & Estudo & Trabalho & $\begin{array}{c}\text { Estudo } \\
\text { /trab. }\end{array}$ & Total \\
\hline $\begin{array}{c}\text { Ótimo } \\
\text { /Bom }\end{array}$ & $60,0 \%$ & $50,0 \%$ & $52,8 \%$ & $55,1 \%$ & $57,1 \%$ & $66,1 \%$ & $45,3 \%$ & $69,2 \%$ & $55,3 \%$ & $51,7 \%$ & $55,0 \%$ \\
\hline Regular & $26,7 \%$ & $38,3 \%$ & $38,9 \%$ & $26,5 \%$ & $34,3 \%$ & $23,2 \%$ & $40,6 \%$ & $30,8 \%$ & $27,7 \%$ & $36,7 \%$ & $32,5 \%$ \\
\hline $\begin{array}{c}\text { Ruim } \\
\text { /Péssimo }\end{array}$ & $13,3 \%$ & $11,7 \%$ & $8,3 \%$ & $18,4 \%$ & $8,6 \%$ & $10,7 \%$ & $14,1 \%$ & $0,0 \%$ & $17,0 \%$ & $11,7 \%$ & $12,5 \%$ \\
\hline Total & $100 \%$ & $100 \%$ & $100 \%$ & $100 \%$ & $100 \%$ & $100 \%$ & $100 \%$ & $100 \%$ & $100 \%$ & $100 \%$ & $100 \%$ \\
\hline
\end{tabular}

Fonte. Dados da pesquisa (2019)

Assim, conforme Tavares, De Almeida e Machado (2018) a vitrine e o visual são importantes para atrair e cria uma identidade de uma loja, pois permite apresentar um produto para a venda por meio de um diálogo entre a empresa e o comprador, e de certa forma as mulheres são grande influenciadores e críticas nessa questão, tal fato corroborado pela pesquisa.

O Quadro 14 objetiva analisar a opinião dos consumidores quanto ao pós-compra, isto é, o contato com a loja após a compra. 


\begin{tabular}{|c|c|c|c|c|c|c|c|c|c|c|c|}
\hline \multicolumn{10}{|c|}{ Quadro 14. O contato da empresa após a compra (pós-venda) } \\
\hline & Fem. & Masc. & Até 20 & $\mathbf{2 1 / 3 0}$ & $\mathbf{3 0}+$ & $\begin{array}{c}\mathbf{1} / \mathbf{2} \\
\text { grau }\end{array}$ & $\mathbf{3}$ grau & Estudo & Trab. & Est. e Trab. & Total \\
\hline $\begin{array}{c}\text { Ótimo } \\
\text { /Bom }\end{array}$ & $26,7 \%$ & $20,0 \%$ & $25,0 \%$ & $18,4 \%$ & $28,6 \%$ & $28,6 \%$ & $18,8 \%$ & $38,5 \%$ & $25,5 \%$ & $18,3 \%$ & $23,3 \%$ \\
\hline Regular & $26,7 \%$ & $25,0 \%$ & $22,2 \%$ & $28,6 \%$ & $25,7 \%$ & $23,2 \%$ & $28,1 \%$ & $7,7 \%$ & $23,4 \%$ & $31,7 \%$ & $25,8 \%$ \\
\hline $\begin{array}{c}\text { Ruim } \\
\text { /Péssimo }\end{array}$ & $46,7 \%$ & $55,0 \%$ & $52,8 \%$ & $53,1 \%$ & $45,7 \%$ & $48,2 \%$ & $53,1 \%$ & $53,8 \%$ & $51,1 \%$ & $50,0 \%$ & $50,8 \%$ \\
\hline Total & $100 \%$ & $100 \%$ & $100 \%$ & $100 \%$ & $100 \%$ & $100 \%$ & $100 \%$ & $100 \%$ & $100 \%$ & $100 \%$ & $100 \%$ \\
\hline
\end{tabular}

Fonte. Dados da pesquisa (2019)

Nesta variável, destaca-se que 50,8\% dos clientes classificam como ruim/péssimo, sendo o sexo masculino (55\%) mais crítico juntamente entre aqueles com ensino superior $(53,1 \%)$. Tal número reforça a importância do marketing de relacionamento e a necessidade das empresas ter um programa de pós-venda que estimule a fidelização, procurando torná-la distinta das concorrentes (CAMARGO, 2018). É preciso ouvir os clientes, suas sugestões e reclamações, e exercer o marketing de relacionamento com os clientes (RODRIGUES; SILVA; ANDRADE, 2011; ARAUJO; LOPES, 2019).

Em resumo, considerando os resultados do estudo, de acordo com o Quadro 15, verifica-se que a variável de melhor avaliação foi em relação a "higiene e limpeza das lojas", com 75\% de "ótimo/bom", e que provavelmente esse é o motivo de atrair consumidores de outras cidades.

Por outro lado, a variável de menor avaliação de "ótimo/bom" refere-se ao contato após a compra, com apenas $23,8 \%$, o que, de certa forma, pode traduzir a cultura local dos comerciantes em relação a essas práticas, em que o pós venda, ainda precisa ser melhorado.

Quadro 15. Resumo geral dos resultados

\begin{tabular}{|c|c|c|c|c|}
\hline & $\begin{array}{c}\text { Ótimo/ } \\
\text { Bom }\end{array}$ & Regular & $\begin{array}{c}\text { Ruim/ } \\
\text { Péssimo }\end{array}$ & Total \\
\hline Quadro 5 - Educação e cordialidade dos vendedores & $55,8 \%$ & $33,3 \%$ & $10,8 \%$ & $100,0 \%$ \\
\hline Quadro 6 - Qualidade do atendimento dos vendedores & $54,2 \%$ & $37,5 \%$ & $8,3 \%$ & $100,0 \%$ \\
\hline Quadro 7 - Rapidez no atendimento dos vendedores & $45,0 \%$ & $46,7 \%$ & $8,3 \%$ & $100,0 \%$ \\
\hline Quadro 8 - Higiene/limpeza das lojas & $75,0 \%$ & $21,7 \%$ & $3,3 \%$ & $100,0 \%$ \\
\hline Quadro 9 - Preços praticados no comércio local & $26,7 \%$ & $43,3 \%$ & $30,0 \%$ & $100,0 \%$ \\
\hline Quadro 10 - Promoções oferecidas pelo comércio & $43,3 \%$ & $40,0 \%$ & $16,7 \%$ & $100,0 \%$ \\
\hline Quadro 11 - Qualidade dos produtos oferecidos & $58,3 \%$ & $33,3 \%$ & $8,3 \%$ & $100,0 \%$ \\
\hline Quadro 12 - Variedade de produtos na cidade & $43,3 \%$ & $32,5 \%$ & $24,2 \%$ & $100,0 \%$ \\
\hline Quadro 13 - Vitrines/fachadas como decoração e beleza & $55,0 \%$ & $32,5 \%$ & $12,5 \%$ & $100,0 \%$ \\
\hline Quadro 14 - O contato da empresa após a compra (pós-venda) & $23,8 \%$ & $25,8 \%$ & $50,8 \%$ & $100,0 \%$ \\
\hline
\end{tabular}

Fonte. Dados da pesquisa (2019)

Para finalizar a análise, por meio do Quadro 16, apresenta-se o resultado do teste não paramétrico, Qui Quadrado, onde aponta se deve ou não rejeitar a hipótese pressuposta inicialmente na metodologia ao grau de significância de 5\% que é H0: não há diferença significativa quanto a compreensão sobre avaliação do comércio de uma cidade do Paraná, considerando as variáveis: gênero, faixa etária, escolaridade e como se enquadra (trabalha, estuda ou ambos). 
Quadro 16. Resumo do teste estatístico não paramétrico Qui-Quadrado

\begin{tabular}{|c|c|c|c|c|c|c|c|c|}
\hline & $\begin{array}{l}\text { P- } \\
\text { valor }\end{array}$ & $\begin{array}{c}\text { Teste } \\
\text { hipótese: } \\
\text { Sexo }\end{array}$ & $\begin{array}{c}\text { P- } \\
\text { valor }\end{array}$ & $\begin{array}{c}\text { Teste } \\
\text { hipótese: } \\
\text { Faixa etária }\end{array}$ & $\begin{array}{c}\text { P- } \\
\text { valor }\end{array}$ & $\begin{array}{c}\text { Teste } \\
\text { hipótese: } \\
\text { Ensino }\end{array}$ & $\begin{array}{c}\text { P- } \\
\text { valor }\end{array}$ & $\begin{array}{c}\text { Teste } \\
\text { hipótese: } \\
\text { Ocupação }\end{array}$ \\
\hline Quadro 5 & 0,34 & $\begin{array}{c}\text { Aceita-se } \\
\text { H0 }\end{array}$ & 0,25 & $\begin{array}{c}\text { Aceita-se } \\
\text { H0 }\end{array}$ & 0,19 & $\begin{array}{c}\text { Aceita-se } \\
\text { H0 }\end{array}$ & 0,97 & Aceita-se $\mathrm{H} 0$ \\
\hline Quadro 6 & 0,12 & $\begin{array}{c}\text { Aceita-se } \\
\text { H0 }\end{array}$ & 0,34 & $\begin{array}{c}\text { Aceita-se } \\
\text { H0 }\end{array}$ & 0,19 & $\begin{array}{c}\text { Aceita-se } \\
\text { H0 }\end{array}$ & 0,38 & Aceita-se $\mathrm{H} 0$ \\
\hline Quadro 7 & 0,18 & $\begin{array}{c}\text { Aceita-se } \\
\text { H0 }\end{array}$ & $0,02 *$ & $\begin{array}{c}\text { Rejeita-se } \\
\text { H0 }\end{array}$ & 0,77 & $\begin{array}{c}\text { Aceita-se } \\
\text { H0 }\end{array}$ & 0,49 & Aceita-se $\mathrm{H} 0$ \\
\hline Quadro 8 & 0,59 & $\begin{array}{c}\text { Aceita-se } \\
\text { H0 }\end{array}$ & 0,30 & $\begin{array}{c}\text { Aceita-se } \\
\text { H0 }\end{array}$ & 0,51 & $\begin{array}{c}\text { Aceita-se } \\
\text { H0 }\end{array}$ & 0,88 & Aceita-se $\mathrm{H} 0$ \\
\hline Quadro 9 & 0,22 & $\begin{array}{c}\text { Aceita-se } \\
\text { H0 }\end{array}$ & 0,06 & $\begin{array}{c}\text { Aceita-se } \\
\text { H0 }\end{array}$ & 0,86 & $\begin{array}{c}\text { Aceita-se } \\
\text { H0 }\end{array}$ & $0,03 *$ & $\begin{array}{c}\text { Rejeita-se } \\
\text { H0 }\end{array}$ \\
\hline Quadro 10 & 0,45 & $\begin{array}{c}\text { Aceita-se } \\
\text { H0 }\end{array}$ & 0,70 & $\begin{array}{c}\text { Aceita-se } \\
\text { H0 }\end{array}$ & 0,26 & $\begin{array}{c}\text { Aceita-se } \\
\text { H0 }\end{array}$ & 0,86 & Aceita-se $\mathrm{H} 0$ \\
\hline Quadro 11 & 0,46 & $\begin{array}{c}\text { Aceita-se } \\
\text { H0 }\end{array}$ & 0,88 & $\begin{array}{c}\text { Aceita-se } \\
\text { H0 }\end{array}$ & 0,21 & $\begin{array}{c}\text { Aceita-se } \\
\text { H0 }\end{array}$ & 0,39 & Aceita-se H0 \\
\hline Quadro 12 & 0,39 & $\begin{array}{c}\text { Aceita-se } \\
\text { H0 }\end{array}$ & 0,67 & $\begin{array}{c}\text { Aceita-se } \\
\text { H0 }\end{array}$ & 0,98 & $\begin{array}{c}\text { Aceita-se } \\
\text { H0 }\end{array}$ & $0,02 *$ & $\begin{array}{c}\text { Rejeita-se } \\
\text { H0 }\end{array}$ \\
\hline Quadro 13 & 0,39 & $\begin{array}{c}\text { Aceita-se } \\
\text { H0 }\end{array}$ & 0,49 & $\begin{array}{c}\text { Aceita-se } \\
\text { H0 }\end{array}$ & 0,06 & $\begin{array}{c}\text { Aceita-se } \\
\text { H0 }\end{array}$ & 0,72 & Aceita-se $\mathrm{H} 0$ \\
\hline Quadro 14 & 0,60 & $\begin{array}{c}\text { Aceita-se } \\
\text { H0 }\end{array}$ & 0,81 & $\begin{array}{c}\text { Aceita-se } \\
\text { H0 }\end{array}$ & 0,43 & $\begin{array}{c}\text { Aceita-se } \\
\text { H0 }\end{array}$ & 0,33 & Aceita-se H0 \\
\hline
\end{tabular}

Fonte. Dados da pesquisa (2019). Nota. * significativo a 5\% $(\mathrm{p}<0,05)$

Assim, verifica-se as considerações, quando deve rejeitar H0, elucidando a diferença encontrada entre os grupos pesquisados:

i) No Quadro 7, que aborda sobre "rapidez no atendimento dos vendedores", segmentado por faixa etária (p-valor: 0,02 ), há diferença significativa ao nível de significância de $5 \%$, assim, rejeita-se a hipótese $\mathrm{H} 0$, pois quem tem a faixa etária até 20 anos avalia como ótimo/bom, com 50\%; já os com faixa etária de 21 a 30 avaliam como ótimo/bom, com 49\%, e os com faixa etária 30+ avaliam com 34,3\%; isso mostra que os entrevistados de maior faixa etária são mais críticos, isto é, exigentes.

ii) No Quadro 9, que aborda os "preços praticados no comércio local", no segmento ocupação (p-valor: 0,03 ) há diferença significativa ao nível de significância de $5 \%$; deste modo, rejeita-se a hipótese $\mathrm{H} 0$, porque houve empate entre a mesma ocupação (os que apenas estudam) em ótimo/bom e péssimo/ruim, sendo as duas variáveis avaliadas com $38,5 \%$; já quem apenas trabalha avalia os preços praticados no comércio como péssimo/ruim, com 42,6\%; e quem trabalha e estuda avalia como regular, com 55\%.

iii) No Quadro 12, referente à "variedade de produtos na cidade", na segmentação ocupação (p-valor: 0,02 ) há diferença significativa ao nível de significância de $5 \%$, desta forma rejeita-se a hipótese $\mathrm{H} 0$, uma vez que quem apenas estuda avalia a variedade do comércio como regular, com $76,9 \%$; já quem apenas trabalha avalia como ótimo/bom, com 42,6\%; e os que estudam e trabalham avaliam também como ótimo/bom, com 48,3\%.

\section{CONCLUSÃO}

O objetivo do trabalho foi atingido, uma vez que procurou analisar a satisfação dos clientes em relação ao comércio de uma cidade do estado do Paraná.

Quanto aos resultados obtidos, percebe-se que, em geral, a avaliação dos consumidores em relação ao comércio é boa, com exceção dos itens relativo ao preço e atendimento pós-compra, classificados como ruim/péssimo, respectivamente com 30\% e 
50,8\% de citação. Os demais itens predominam com avaliação ótimo/bom. Ainda assim, a classificação não foi muito alta, e em muitos quesitos a soma de ruim/péssimo com regular forma a maioria das avaliações.

Quanto ao primeiro objetivo específico, que busca analisar a satisfação referente ao conforto e ao ambiente oferecido, percebe-se que no fator higiene e limpeza das lojas, 75\% dos clientes classificam como ótimo/bom; e em relação à vitrine/fachada, 55\% classificam também como ótimo/bom. Sendo assim, constatou-se que a maioria absoluta dos consumidores classificam esses itens de forma positiva.

Em relação ao produto, preço, promoção e pós-compra, percebe-se que as avaliações não foram tão positivas, uma vez que em nenhum dos aspectos abordados as avaliações positivas representam a maioria absoluta à exceção do item qualidade dos produtos avaliado positivamente por $58,3 \%$ dos entrevistados, sendo o fator preço avaliado por $43,3 \%$ dos consumidores como regular (o segundo item pior avaliado) e atendimento pós-compra avaliado como ruim/péssimo por $50,8 \%$ dos entrevistados (a pior avaliação), e a variedade dos produtos e a promoção oferecidas ambas como ótimo/bom por $43,3 \%$ dos consumidores.

Por fim, em relação à qualidade do atendimento no comércio, as avaliações são boas, à exceção do item rapidez, avaliado como regular por $46,7 \%$ dos participantes; o atendimento dos vendedores e educação e cordialidade são percebidos como ótimo/bom por $54,2 \%$ e $55,8 \%$ dos entrevistados respectivamente.

Como contribuição da pesquisa, ela ofereceu dados empíricos que indicam a opinião dos consumidores em relação ao comércio da cidade e isso pode auxiliar a associação comercial da cidade criar estratégicas específicas para cada variável investigada.

A limitação da pesquisa foi quanto ao tamanho da amostra por se tratar de amostragem não probabilística, não permitindo inferência dos resultados. Para uma cidade com mais de 30.000 habitantes, uma amostra com 120 clientes, apesar de apontar um norte e orientação, pode trazer resultados um pouco imprecisos.

A análise também serve como base para trabalhos futuros, a fim de servir de apoio para eventuais pesquisas que visem compreender a visão dos clientes quanto ao comércio da cidade, para uma abordagem sobre quais razões os fazem comprar aqui, ou em outras cidades, entre outros. Da mesma forma também, permitirá gerar conteúdo para a academia e aos pesquisadores que estuda e trabalha na produção acadêmica no contexto do varejo.

\section{REFERÊNCIAS}

ARAUJO, L. C. Q.; LOPES, A. E. M. P. Marketing de relacionamento para o sucesso empresarial das microempresas do varejo: um estudo de caso da empresa ótica Dennys no município de Bragança-Pa. REPAE-Revista de Ensino e Pesquisa em Administração e Engenharia, v. 5, n. 1, p. 33-79, 2019.

BERRO, D.. Atendimento pós-venda: gestão estratégica da excelência - 2010. Disponível em: <http://www.administradores.com.br>. Acesso em: 02 de agosto de 2019.

BEZERRA, I. S. Qualidade do ponto de vista do cliente. São Paulo: Biblioteca 24 horas, 2013.

BRITO, E. P Z.; VIEIRA, V. A.; ESPARTEL, L. B. A pesquisa na área do varejo: reflexões e provocações. Revista de Administração de Empresas, v. 51, n. 6, p. 522$527,2011$. 
CAMARGO, P. S. G et al. As contribuições da utilização do marketing de relacionamento nos resultados das vendas. Facit Business and Technology Journal, v. 1, n. 6, 2018.

CASTRO, M. de S. Ouvidoria Bancária: O Itaú Unibanco - UNILASALLE/RJ 2012. Disponível em:<www.administradores.com.br/.../ouvidoria>. Acesso em: 01 de agosto de 2019.

COMIOTTO, F.D. et al. Comprei meu carro, o que vem depois analise da percepção e da importância atribuídas por clientes em serviços de pós venda. Revista Brasileira de Marketing - ReMARK, v.13, n.6, 2014.

COSTA, A. S. C.; SANTANA, L.C.; TRIGO, A. C. Qualidade do atendimento ao cliente: um grande diferencial competitivo para as organizações. Revista de Iniciação Científica - RIC Cairu. Jun. 2015, Vol 02, $n^{\circ}$ 02, p. 155-172.

DA SILVA, D. F. et al. Promoção de vendas: uma ferramenta estratégica para a fidelização de clientes em tempos de crise. REINPEC-Revista Interdisciplinar Pensamento Científico, v. 2, n. 1, 2016.

DA SILVA MELO, J. L.; DA SILVA, N. O.; QUEVEDO, A. P F. Gestão da Qualidade e Princípio da Eficiência: uma Análise da Prestação de Serviços nas Universidades Públicas da Cidade de Petrolina-PE. Id on line revista multidisciplinar e de psicologia, 2016, 10.30: 131-143.

DANTAS, E. B. Gestão da informação sobre a satisfação de consumidores e clientes: condição primordial na orientação para o mercado. São Paulo: Atlas, 2014.

DEMO, P. Metodologia do conhecimento científico. São Paulo: Atlas, 2000.

EISNER, M. O jeito Disney de encantar os clientes. Ed. Saraiva, São Paulo, 2011.

ESPINOZA, F.; D'ANGELO, A. C.; LIBERALI, G. A influência da atmosfera de varejo sobre os consumidores. Revista de Administração-RAUSP, v. 40, n. 2, p. 109-122, 2005.

FONSECA, J. J. S. Metodologia da pesquisa científica. Fortaleza: UEC, 2002.

GARCIA, M. T. Comportamento do Consumidor. Rio de Janeiro: Gama Filho, 2011.

GIANESI, I. G.; CORRÊA, H. L. Administração Estratégica de Serviços: operações para a satisfação do cliente. São Paulo: Atlas, 1996.

GIL, A. C. Como elaborar projetos de pesquisa. 6. ed. São Paulo: Atlas, 2017.

HAYES, B. E. Medindo a satisfação do cliente: desenvolvimento e uso de questionários. Rio de Janeiro: Qualitymark, 1992.

HOFFMANN, K. D.; BATESON, J. E G. Princípios marketing de serviço: conceitos, estratégias e casos. $2^{\text {a }}$ ed. São Paulo: Cengage Learning, 2008.

KOTLER, P.; KELlER, K. L. Administração de Marketing. 12. Edição. São Paulo, Pearson Prentice Hall, 2006

KOTLER, P.; ARMSTRONG, G. Princípios de Marketing. 14. ed. São Paulo: Prentice Hall, 2014.

LARENTIS, F. Comportamento do consumidor. Ed. Iesde Brasil S/A, Curitiba, PR 2012. 
LARAN, J. A.; ESPINOZA, F da S. Consumidores satisfeitos, e então? Analisando a satisfação como antecedente da lealdade. Revista de administração contemporânea, Curitiba, v. 8, n. 2, p. 51-70, 2004.

LAS CASAS, A. L. Administração de marketing: conceitos, planejamento e aplicações à realidade brasileira. 4 ed. São Paulo: Atlas, 2010.

LEVITT, T. A imaginação de marketing. São Paulo: Atlas, 1990.

LOPES, E. L. et al. O novo consumidor idoso: identificação dos atributos varejistas relevantes. RAE-Revista de Administração de Empresas, v. 53, n. 6, p. 551-564, 2013.

MATTAR, F. N. Pesquisa de marketing. 3 ed. São Paulo, Atlas, 2001.

MORAIS, A. S. A. de et al. Práticas de gestão de marketing multicanal: estudo no varejo de bens de consumo. Contextus - Revista Contemporânea de Economia e Gestão, [s.1.], v. 16, n. 3, p.66-100, 12 dez. 2018.

PINHEIRO, R. M. et al. Comportamento do consumidor. Rio de Janeiro: FGV editora, 2011.

RODRIGUES, K.P.; SILVA, L.C.D.; ANDRADE, A.P. Uma análise das ações de pósvenda como estratégia de fidelização. VIII Convibra Administração. Congresso Virtual Brasileiro de Administração, 2011.

SAMPIERI, R. H. et al. Metodologia da investigação. México: McGraw-Hill, 1991.

SAUSEN, J. F. C. L. et al. Marketing sensorial: limites e possibilidades no varejo físico e virtual de vestuário. Anais do Simpósio Latino-Americano de Estudos de Desenvolvimento Regional, v. 1, n. 1, 2018.

SIEGEL, S.; CASTELLAN Jr, N. J. Estatística Não Paramétrica para as Ciências do Comportamento. Artmed-Bookman. São Paulo, 2017.

SOBRINHO, C. O serviço Pós-Venda como um diferencial. Revista Super Meio \& Mídia - 2005. Disponível em: http://www.estruturadinamica.com.br/artigo005.html. Acesso em: 29 de julho de 2019.

SOLOMON, M. R. O comportamento do consumidor: comprando, possuindo e sendo. 11 ed. Porto Alegre - RS: Bookman, 2016.

TAVARES, F. V.; DE ALMEIDA, S. O.; MACHADO, M. A. D. A Primeira Impressão é a que Fica: A Influência da Vitrine na Decisão de Compra. In: CLAV 2018. 2018.

TRIVIÑOS, A. N. S. Introdução à pesquisa em ciências sociais: a pesquisa qualitativa em educação. São Paulo: Atlas, 1987.

ZACHARIAS, M. L. B.; FIGUEIREDO, K F; DE ALMEIDA, V. M. C. Determinantes da satisfação dos clientes com serviços bancários. RAE-eletrônica, v. 7, n. 2, 2008. 